\title{
SESN2 correlates with advantageous prognosis in hepatocellular carcinoma
}

\author{
Shaosen Chen ${ }^{1 \dagger}$, Weigang Yan ${ }^{2 \dagger}$, Weiya Lang ${ }^{3}$, Jing Yu${ }^{4}$, Li Xu ${ }^{5}$, Xinyu Xu ${ }^{5}$, Yunlong $\mathrm{Liu}^{1 *}$ and Hongguang Bao ${ }^{1 *}$
}

\begin{abstract}
Background: SESN2 plays important roles in the regulation of cell survival, cell protection, and tumor suppression. However, the relationship between SESN2 expression and the clinicopathological attributes of hepatocellular carcinoma (HCC) is barely investigated.

Methods: One-step quantitative reverse transcription PCR, Western blotting analysis in 15 fresh HCC tissues, and immunohistochemistry (IHC) analysis in a tissue microarray (TMA) containing $100 \mathrm{HCC}$ cases were performed to examine SESN2 expression. Survival analyses by Cox regression method and Kaplan-Meier curve were performed to describe the overall survival of 100 HCC patients.

Results: The SESN2 expression in HCC tissues declined dramatically compared with the corresponding noncancerous tissues, and SESN2 expression was remarkably associated with HBV infection $(p=0.019)$, HCV infection $(p=0.001)$, and lymph node metastasis $(p=0.033)$. Survival analysis further demonstrated that SESN2 expression could serve as an independent prognostic biomarker for overall survival in univariate $(p=0.001)$ and multivariate analyses $(p=0.003)$.

Conclusion: The data are the first to indicate that SESN2 might be a novel prognostic marker for HCC and that elevated SESN2 expression predicts advantageous outcomes in HCC patients.
\end{abstract}

Keywords: SESN2, qPCR, Western blotting, IHC, Hepatocellular carcinoma

\section{Background}

Hepatocellular carcinoma (HCC) represents the fifth most common cancer type and causes more than 500,000 cancer-related deaths every year worldwide [13]. Although the majority of HCC cases develop in Asia, cases in China account for more than half of initially diagnosed HCC patients all over the world, and the city of Qidong in East China is one of the most highly endemic areas for HCC $[4,5]$. The etiology of HCC is diverse and complicated; hepatitis B (HBV) and hepatitis C (HCV) viral infections as well as liver cirrhosis often contribute to HCC development [6, 7]. Despite substantial improvements in HCC management, including surgical resection, microwave ablation, liver transplantation, radiofrequency and chemotherapy, over the last 10 years, the prognosis of HCC remains unsatisfactory; moreover, the 5 -year overall survival rate is less than $30 \%[8,9]$.

\footnotetext{
* Correspondence: lylqqhe@126.com; bhg28k@163.com

${ }^{\dagger}$ Equal contributors

${ }^{1}$ Department of Thoracic Surgery and Oncology, the No. 2 Affiliated Hospital of Qiqhar Medical University, Qiqhar 161000, China

Full list of author information is available at the end of the article
}

For now, alpha-fetoprotein (AFP) is still the most widely acknowledged marker in early detection and follow-up surveillance for HCC [10]. However, because of the number of AFP negative HCC patients and the inadequate understanding of the molecular mechanism of HCC tumorigenesis, studies focusing on the novel biomarkers that are involved in the carcinogenic process of HCC development and correlated with malignant characteristics of HCC are urgently needed [11].

SESN2, is transcriptionally regulated by $\mathrm{p} 53$, and belongs to the evolutionarily conserved sestrin family [12]. As a critical downstream effector of p53, SESN2 could be induced in a p53-dependent manner, such as with DNA damaging treatments, or in a p53-independent manner, including hypoxia or oxidative stress $[12,13]$. SESN2 is involved in the regulation of cell survival, protection, and regeneration [14, 15]. Moreover, SESN2 acts as an important contributor in autophagy induction and tumor suppression [16, 17]. For example, SESN2 expression could be increased via the c-Jun N-terminal kinase (JNK) pathway to influence autophagy induction in 
cancer cells $[9,18]$. Several gene expression analyses have also shown down-regulated SESN2 expression in different types of lung cancers $[19,20]$. In addition, SESN2 expression inhibits cancer growth while increasing the sensitivity of cancer cells to ionizing radiation [15, 21]. The upregulation of SESN2 can also induce apoptosis through the p53 signaling pathway [22]. These studies suggest that SESN2 acts as a multifunctional molecule and is critically associated with tumor development. Nevertheless, the characteristics of SESN2 expression in HCC have been barely investigated.

To explore SESN2 expression in this study, we first detected the SESN2 expression using one-step quantitative-polymerase chain reaction (qPCR) test and Western blotting analysis in 15 fresh HCC tissues. Subsequently, we performed immunohistochemistry (IHC) analysis in a tissue microarray (TMA) containing 100 HCC tissue samples. Then, we analyzed the correlations of SESN2 expression with important clinicopathological characteristics of HCC patients. Finally we evaluated the prognostic role of SESN2 expression for HCC.

\section{Methods}

\section{Tissue samples}

Fifteen fresh HCC tissue samples and corresponding noncancerous tissue samples were collected from the Department of Surgery, the No.2 Affiliated Hospital of Qiqhar Medical University from May 2013 to Dec 2013. Simultaneously, 100 formalin-fixed, paraffin-embedded HCC and corresponding noncancerous tissue samples (each pair of HCC and corresponding noncancerous sample was from the same patient) were collected from the Department of Surgery, the No.2 Affiliated Hospital of Qiqhar Medical University (10 samples) and Xinchao Biotech Co., Ltd (90 samples) (Shanghai, China) for retrospective analyze. The HCC TMA from Xinchao Biotech Co., Ltd was described in a previous study [23]. No patients received chemotherapy, radio therapy or other immunotherapy before hepatic surgery. Substantial clinical data were also recorded in 2013, including gender, age, HBV infection, HCV infection, liver cirrhosis, tumor size etc. from medical records (10 samples) and purchased tissue microarray samples (90 samples). All 100 HCC samples of TMA were entered into the survival analyses. Clinical staging was classified according to the 2002 American Joint Committee on Cancer/International Union Against Cancer TNM staging system [24]. All enrolled patients signed written informed consent and all experimental procedures were implemented following the approved protocols of Qiqhar Medical University. All authors had access to identifying information during data collection.

\section{Detection of mRNA expression of SESN2 by one-step qPCR test}

One-step qPCR test was performed to detect the mRNA expression of SESN2 preliminarily in 15 fresh HCC and corresponding noncancerous tissue samples following the protocols in our previous publication [25]. The primers for SESN2 were designed as follows: forward primer 5' - AGA GGG CAC AGG AAA GAA-3'; reverse primer 5'-TCA AGC ATA AAG GAC CAA A-3'. The glyceraldehyde 3-phosphate dehydrogenase (GAPDH) was employed as internal control and the primers for GAPDH were as follows: forward primer 5'-TGC ACC ACC AAC TGC TTA GC-3'; reverse primer 5'-CTC

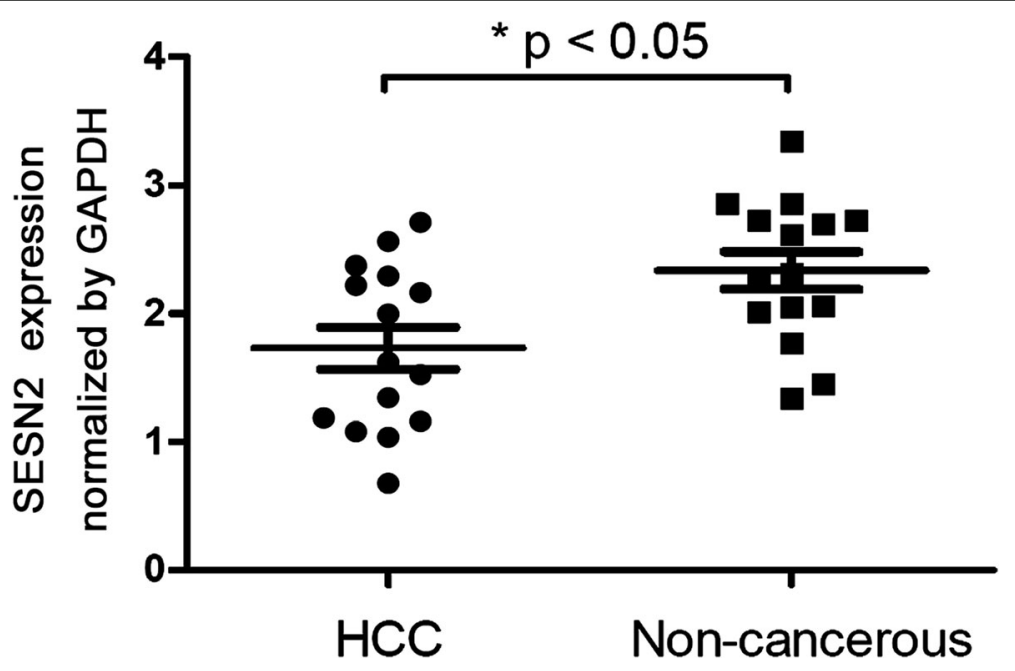

Fig. 1 One-step quantitative real-time polymerase chain reaction (qPCR) test was performed to examine SESN2 expression in hepatocellular carcinoma (HCC) and non-cancerous tissues. The SESN2 mRNA expression was statistically lower in HCC tissues (1.73 \pm 0.165$)$ than that of in the corresponding noncancerous tissues $(2.34 \pm 0.145)(* p<0.05$.) 


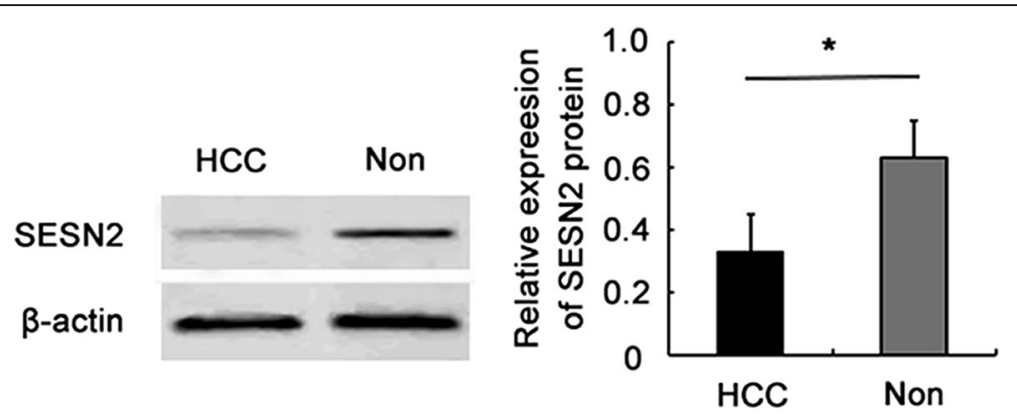

Fig. 2 SESN2 expression detected by western blotting analysis in 15 HCC and noncancerous tissue samples. The expression level of SESN2 in HCC were significantly reduced comparing to that of in noncancerous tissues $(* p<0.05)$

ATG ACC ACA GTC CAT GCC-3'. SensiMixTM OneStep Kits (Quantace, Berlin, Germany) were purchased to execute qPCR test (Bio-Rad PCR system). The data of qPCR test were analyzed using the $2^{-\Delta \Delta \mathrm{Ct}}$ method that was described in the previous studies [25, 26].

\section{Detection of protein expression of SESN2 by western blotting analysis}

Total protein was isolated from $15 \mathrm{HCC}$ and corresponding noncancerous tissue samples. The western blotting analysis was described in previous research [27]. Breifly, total protein was loaded, separated and transferred onto nitrocellulose membrane. The membranes were first incubated with primary mouse monoclonal anti-SESN2 antibody (1: 500, Abcam, ab57810, Cambridge, MA, USA) and secondary antibody (Boster, Wuhan, China). $\beta$-actin (Sigma, USA) was used as an internal control.

\section{Measurement of protein expression of SESN2 by IHC analysis}

IHC analysis was executed to measure the protein expression of SESN2 in a TMA containing $100 \mathrm{HCC}$ and corresponding noncancerous tissue samples following the protocols in a previous publication [27]. HCC TMAs were incubated with a primary mouse monoclonal antiSESN2 antibody (1:250, Abcam, ab57810) and then a second anti-mouse horseradish peroxidase-conjugated antibody (Santa Cruz Biotechnology, Santa Cruz, CA, USA) was added. Phosphate-buffered saline (PBS) was used as negative control. The IHC result was calculated in light of the intensity and percentage of positive staining of SESN2 in HCC cells. The intensity of staining was categorized into 4 levels: level $0=$ negative staining of SESN2, level 1 = weak positive staining of SESN2, level $2=$ moderate positive staining of SESN2, level $3=$ strong positive staining of SESN2. Similarly, the percentage of staining was also ranked into 4 grades: grade $1=0-10 \%$

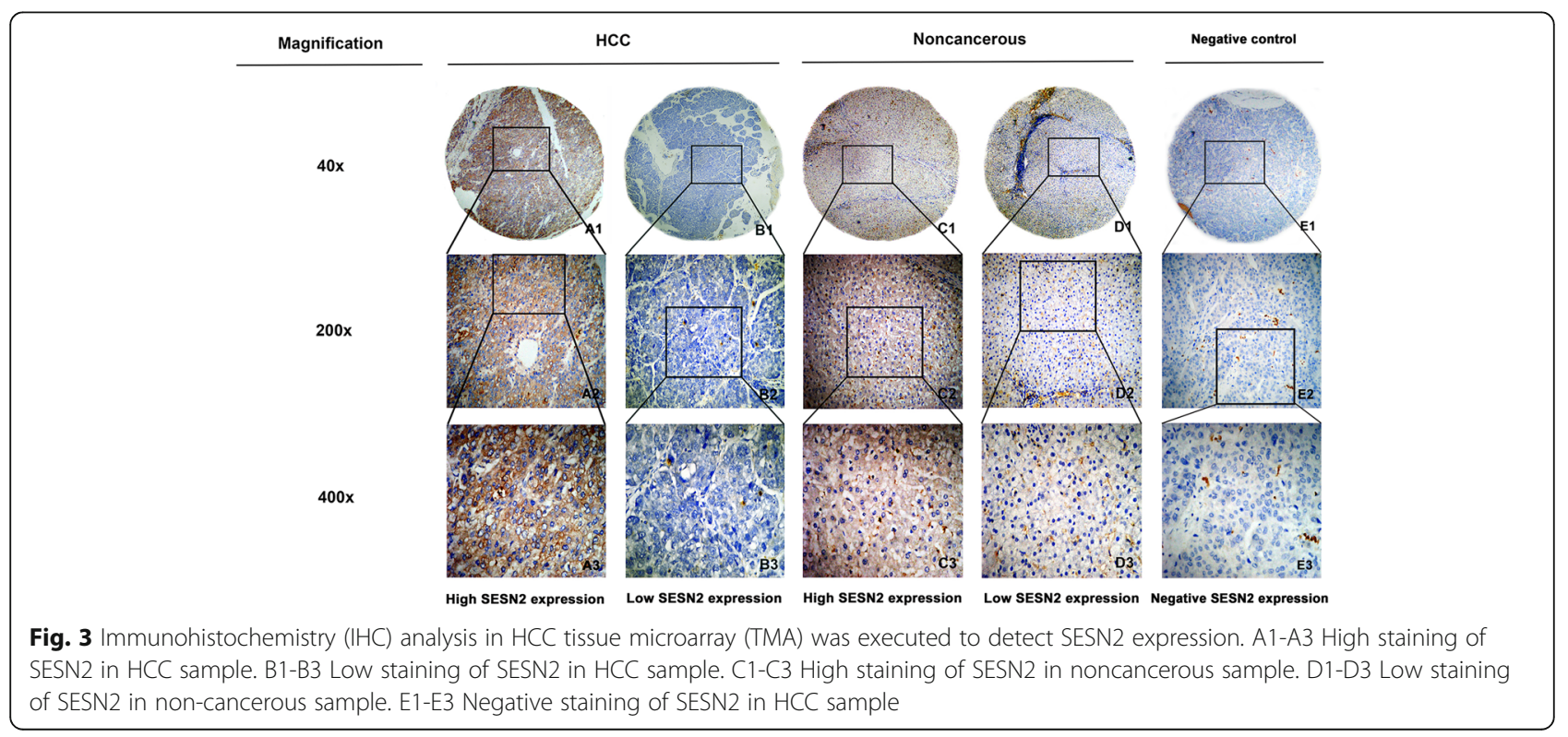


percentage of positive SESN2 staining, grade $2=11-50 \%$ percentage of positive SESN2 staining, grade $3=51-80 \%$ percentage of positive SESN2 staining and grade $4=81-$ $100 \%$ percentage of positive SESN2 staining. The product of the intensity level and percentage grade led to the decisive staining score. The final IHC result of SESN2 staining was defined by a two-level ranking type: $<3$ staining score suggests low SENS2 protein expression while 3-12 staining score suggests high SENS2 protein expression.

\section{Statistical analysis}

The data of qPCR test and western blotting analysis was analyzed with the Student's $t$ test. The relationship between SESN2 expression and clinicopathological factors of HCC patients was analyzed by chi-square test. Survival analysis was accomplished using Cox's regression models. The Kaplan-Meier curve was drawn to determine independent prognostic factors for HCC patients. The level of significance was set at $p<0.05$. All data were analyzed with SPSS 16.0 (SPSS Inc, Chicago, IL, USA).

\section{Results}

Detection of mRNA expression of SESN2 by one-step qPCR test

The result of qPCR test showed that the SESN2 mRNA expression was statistically lower in HCC tissues (1.73 \pm $0.165)$ than that of in the corresponding noncancerous tissues $(2.34 \pm 0.145)(\mathrm{t}=2.759, p=0.01$, Fig. 1$)$.

\section{Detection of protein expression of SESN2 by western blotting analysis}

Western blotting analysis in $15 \mathrm{HCC}$ and corresponding noncancerous tissue samples was performed to evaluate the protein expression of SESN2. The results showed the similar trend in qPCR test that SESN2 expression in $\mathrm{HCC}$ tissues was statistically lower than that of in noncancerous tissues (Fig. 2).

\section{Measurement of protein expression of SESN2 by IHC analysis}

The data of IHC analysis demonstrated that high SESN2 expression was observed in 38 of 100 HCC tissue samples $(38.0 \%)$, whereas 71 of 100 noncancerous normal tissue cases $(71.0 \%)$ showed high SESN2 expression. In HCC tissues, the SESN2 protein expression level was significantly reduced compared to noncancerous tissues $(p$ $<0.05$ ). Positive staining of SESN2 was mainly located in the cytoplasm of HCC cells (Fig. 3).

\section{Association between SESN2 protein expression and} clinicopathological characteristics of HCC

The association between high SESN2 protein expression and the clinicopathological characteristics of $100 \mathrm{HCC}$ patients are shown in Table 1. SESN2 expression was associated with HBV infection $(p=0.019)$, HCV infection $(p=0.001)$ and lymph node metastasis $(p=0.033)$. In contrast, no statistical association was noticed between SESN2 expression and other clinical items, including the gender, age, liver cirrhosis, tumor size, distant metastasis, and TNM stage (Table 1).

\section{Survival analysis}

For survival analysis, univariate test was firstly performed and the results stated that the prognosis of 100 HCC patients was significantly correlated with the SESN2 expression level $(p=0.001)$, HCV infection $(p=$ $0.036)$, lymph node metastasis $(p=0.001)$, distant metastasis $(p=0.003)$, and TNM stage $(p=0.001)$. Subsequently, multivariate test further screened that SESN2

Table 1 Relationship of high SESN2 expression with clinicopathological characteristics in HCC

\begin{tabular}{|c|c|c|c|c|c|}
\hline \multirow[t]{2}{*}{ Groups } & \multirow[t]{2}{*}{ No. } & \multicolumn{2}{|c|}{ SESN2 } & \multirow[t]{2}{*}{$x^{2}$} & \multirow[t]{2}{*}{$p$ value } \\
\hline & & + & $\%$ & & \\
\hline \multicolumn{6}{|l|}{ Gender } \\
\hline Male & 83 & 31 & 37.3 & 0.088 & 0.767 \\
\hline Female & 17 & 7 & 41.2 & & \\
\hline \multicolumn{6}{|l|}{ Age (years) } \\
\hline$<60$ & 58 & 18 & 31.0 & 2.844 & 0.092 \\
\hline$\geq 60$ & 42 & 20 & 47.6 & & \\
\hline \multicolumn{6}{|c|}{ Hepatitis B virus infection } \\
\hline Positive & 41 & 10 & 24.4 & 5.463 & $0.019 *$ \\
\hline Negative & 59 & 28 & 47.5 & & \\
\hline \multicolumn{6}{|c|}{ Hepatitis C virus infection } \\
\hline Positive & 52 & 31 & 59.6 & 21.484 & $0.001^{*}$ \\
\hline Negative & 48 & 7 & 14.6 & & \\
\hline \multicolumn{6}{|l|}{ Liver cirrhosis } \\
\hline Positive & 58 & 21 & 36.2 & 0.189 & 0.664 \\
\hline Negative & 42 & 17 & 40.5 & & \\
\hline \multicolumn{6}{|c|}{ Tumor size (cm) } \\
\hline$>5$ & 57 & 19 & 33.3 & 1.225 & 0.268 \\
\hline$\leq 5$ & 43 & 19 & 44.2 & & \\
\hline \multicolumn{6}{|c|}{ Lymph node metastasis } \\
\hline Positive & 31 & 7 & 22.6 & 4.534 & $0.033^{*}$ \\
\hline Negative & 69 & 31 & 44.9 & & \\
\hline \multicolumn{6}{|c|}{ Distant metastasis } \\
\hline Positive & 12 & 4 & 33.3 & 0.126 & 0.723 \\
\hline Negative & 88 & 34 & 38.6 & & \\
\hline \multicolumn{6}{|l|}{ TNM stage } \\
\hline Stage I-II & 41 & 17 & 41.5 & 0.354 & 0.552 \\
\hline Stage III-IV & 59 & 21 & 35.6 & & \\
\hline
\end{tabular}


expression $(p=0.003)$ and TNM stage $(p=0.003)$ may serve as two independent prognostic factors for overall survival of $100 \mathrm{HCC}$ patients in the present research (Table 2). Kaplan-Meier curves explained that HCC patients with high SESN2 protein expression and early TNM staging had significantly more favorable survival times (Fig. 4).

\section{Discussion}

Sestrins are a family of highly conserved, stressinducible genes that can protect cells against oxidative damage and oncogenic signaling [28]. Recently, one member of this family, SESN2, has received attention for acting as a tumor suppressor that can inhibit angiogenesis and promote apoptosis [12, 29]. This finding underscores the significance of illustrating the molecular mechanism by which SESN2 affects pathways for metabolism and survival. Sanli et al. reported that SESN2 could facilitate AMPK phosphorylation through a combination effect with a tumor suppressor, LKB1 [30] and increase enzyme auto-phosphorylation in breast cancer [21]. SESN2 expression inhibited cell growth and proliferation by suppressing mTOR through AMPK signaling modulation [15]. High expression of SESN2 was found to induce apoptosis through the AMPK/p38 signaling pathway in colon cancer cells [31]. The induction of SESN2 also enhanced the oxidative stress response and showed protective effectiveness in mice against tumor development through mTOR, and p53/p21-signaling network [32]. The above-mentioned information indicates that SESN2 has anti-oncogenic roles in several human cancers. The detailed relationship between SESN2 expression and clinicopathological significance of HCC deserve further exploration.

In the present study, the qPCR test indicated that the mRNA expression of SESN2 was critically reduced in HCC tissues compared with that in the corresponding noncancerous tissues. Moreover, the results of Western blotting and IHC analyses also demonstrated reduced protein expression of SESN2 in HCC cells relative to noncancerous cells. The above data are consistent with previous studies reporting the inhibited expression of SESN2 in several human cancers $[19,20]$. Moreover, considerable associations of SESN2 expression and crucial clinicpathological characteristics in HCC exist, including $\mathrm{HBV}$ and $\mathrm{HCV}$ infection. We found that high SENS2 expression indicated negative lymph node metastasis. Wei et al. also described that low SESN2 expression is correlated with positive lymph node metastasis in colorectal cancer [33]. Our results agree with those

Table 2 Survival analysis by univariate and multivariate methods to identify prognostic factors in HCC

\begin{tabular}{|c|c|c|c|c|c|c|}
\hline & \multicolumn{3}{|c|}{ Univariate analysis } & \multicolumn{3}{|c|}{ Multivariate analysis } \\
\hline & $\mathrm{HR}$ & $p$ value & $95 \% \mathrm{Cl}$ & $\mathrm{HR}$ & $p$ value & $95 \% \mathrm{Cl}$ \\
\hline \multicolumn{7}{|l|}{ SESN2 expression } \\
\hline High versus Low & 0.271 & $0.001^{*}$ & $0.136-0.542$ & 0.308 & $0.003^{*}$ & $0.140-0.678$ \\
\hline \multicolumn{7}{|l|}{ Gender } \\
\hline Male versus Female & 1.140 & 0.732 & $0.539-2.414$ & & & \\
\hline \multicolumn{7}{|l|}{ Age (years) } \\
\hline$<60$ versus $\geq 60$ & 1.630 & 0.084 & $0.937-2.838$ & & & \\
\hline \multicolumn{7}{|l|}{ Hepatitis B virus infection } \\
\hline Positive versus Negative & 1.111 & 0.900 & $0.526-1.539$ & & & \\
\hline \multicolumn{7}{|l|}{ Hepatitis C virus infection } \\
\hline Positive versus Negative & 1.799 & $0.036^{*}$ & $1.039-3.114$ & 0.940 & 0.851 & $0.493-1.793$ \\
\hline \multicolumn{7}{|l|}{ Liver cirrhosis } \\
\hline Positive versus Negative & 1.137 & 0.644 & $0.660-1.959$ & & & \\
\hline \multicolumn{7}{|l|}{ Tumour size (cm) } \\
\hline$>5$ versus $\leq 5$ & 1.412 & 0.219 & $0.814-2.449$ & & & \\
\hline \multicolumn{7}{|l|}{ Lymph node metastasis } \\
\hline Positive versus Negative & 2.795 & $0.001^{*}$ & $1.621-4.821$ & 1.839 & 0.063 & $0.968-3.495$ \\
\hline \multicolumn{7}{|l|}{ Distant metastasis } \\
\hline Positive versus Negative & 2.709 & $0.003^{*}$ & $1.417-5.179$ & 0.925 & 0.846 & $0.421-2.033$ \\
\hline \multicolumn{7}{|l|}{ TNM stage } \\
\hline Stage I-II versus Stage III-IV & 0.276 & $0.001^{*}$ & $0.144-0.527$ & 0.352 & $0.003^{*}$ & $0.178-0.696$ \\
\hline
\end{tabular}



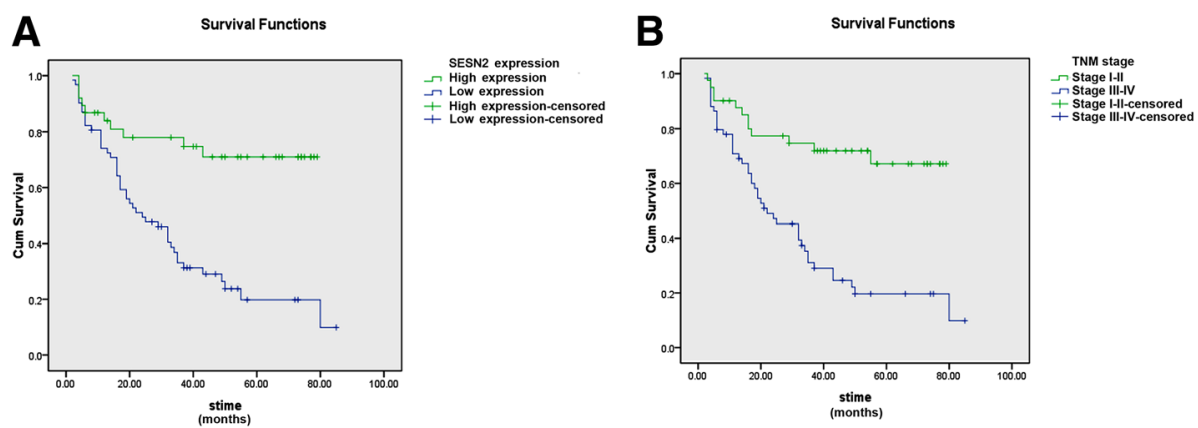

Fig. 4 The Kaplan-Meier curve was drawn to illustrate two independent prognostic factors for overall survival of 100 HCC patients. a Overall survival rate in patients with low SESN2 expression was significantly lower than that in patients with high SESN2 expression. b Overall survival rate in patients with early TNM stage was significantly higher than that in patients with advanced TNM stage

obtained by Wei et al.; SESN2 expression could contribute to the restraint of certain malignant activities in HCC, such as tumor metastasis.

Thus far, studies concerning the association between SESN2 and cancer mortality in clinical samples are rare. In our present research, univariate and multivariate analyses illustrated that SESN2 expression and TNM stage were both correlated with the life span of HCC patients. In addition, the Kaplan-Meier curve analogously proved that HCC patients with low SESN2 expression encountered poor prognosis. The survival results were also in line with those of earlier studies, where high SESN2 expression prohibits tumor development and predicts favorable prognosis in cancers [15, 22, 33]. In all, SESN2 exerts significant anti-oncogenic effects, and high SESN2 expression substantially suspends malignant behavior that facilitates tumor development.

There are some limitations in this study that I need to address. For one thing, we failed to collect some important clinical items for HCC patients, including their AFP values, portal vein invasion statuses and tumor differentiation statuses, which are considered significant elements of the HCC etiology and development. We will perform more comprehensive data collection in our future studies. For another, the application of archived HCC samples may increase the bias in this retrospective observational study. Future studies that enroll more participants are needed to validate the present findings. Finally, the potential manner by which SESN2 influences the tumor microenvironment in HCC has not yet been explored. Future studies are of great importance to explore the mechanism by which SESN2 plays a role in HCC development.

In conclusion, this study first reported the differential expression of SESN2 in HCC. In particular, decreased SESN2 expression was observed in HCC. SESN2 expression was significantly associated with certain malignant behavior of $\mathrm{HCC}$, including $\mathrm{HBV} / \mathrm{HCV}$ infection and lymph node metastasis. Thus, high SESN2 expression implicated advantageous prognosis in $\mathrm{HCC}$ patients. Our current research is valuable in exploring the characteristics of SESN2 in HCC development.

\section{Conclusion}

This work is the first report on both the mRNA and protein expression of SESN2 in HCC. Differential SESN2 expression was detected in $\mathrm{HCC}$ and noncancerous tissue samples, and HCC patients with reduced SESN2 expression levels were prone to suffer positive lymph node metastasis. Moreover, high expression of SESN2 implied advantageous prognosis in $\mathrm{HCC}$ patients.

\section{Abbreviations}

AFP: Alpha-fetoprotein; HBV: Hepatitis B virus; HCC: Hepatocellular carcinoma; HCV: Hepatitis C virus; IHC: Immunohistochemistry; JNK: C-Jun N-terminal kinase; PBS: Phosphate-buffered saline; TMA: Tissue microarray

\section{Acknowledgements \\ None.}

\section{Funding}

None.

\section{Availability of data and materials}

All data were collected and recorded in Microsoft Excel. The clinical materials are stored with the Microsoft Excel files in the Thoracic Surgery and Oncology archives at our institution. All material is available upon request through the corresponding author.

\section{Authors' contributions}

YLL and HGB conceived and designed the study; SSC, WGY, WYL and JY completed the patient collection, data interpretation and GPCR test; LX, and XYX performed the IHC analysis; SSC, WGY and WYL performed the statistical analysis; SSC and YLL drafted the paper; YLL and HGB supervised the study. All authors read and approved the final paper.

\section{Competing interests}

The authors declare that they have no competing interests.

\section{Consent for publication}

Not applicable.

\section{Ethics approval and consent to participate}

All enrolled patients signed written informed consent and all experimental procedures were implemented following the approved protocols of Qiqhar Medical University. 


\section{Author details}

Department of Thoracic Surgery and Oncology, the No. 2 Affiliated Hospital of Qighar Medical University, Qiqhar 161000, China. ${ }^{2}$ Department of Oncology, the First Hospital of Qiqhar City, Qighar 161000, China. ${ }^{3}$ Department of Biochemistry and Molecular Biology, School of Basic Medical Sciences of Qiqhar Medical University, Qiqhar 161000, China. ${ }^{4}$ Department of Histology and Embryology, School of Basic Medical Sciences of Qiqhar Medical University, Qighar 161000, China. ${ }^{5}$ Department of Pathology, Jiangsu Cancer Hospital, Affiliated Cancer Hospital of Nanjing Medical University, Nanjing 210000, China.

\section{Received: 2 June 2016 Accepted: 8 December 2016} Published online: 24 January 2017

\section{References}

1. Gu X, Fu M, Ding Y, Ni H, Zhang W, Zhu Y, Tang X, Xiong L, Li J, Qiu L, et al. TIMP-3 expression associates with malignant behaviors and predicts favorable survival in HCC. PLoS One. 2014;9(8):e106161. doi:10.1371/journal. pone.0106161

2. Fu M, Gu X, Ni H, Zhang W, Chang F, Gong L, Chen X, Li J, Qiu L, Shi C, et al. High expression of inositol polyphosphate phosphatase-like 1 associates with unfavorable survival in hepatocellular carcinoma. Int J Clin Exp Pathol. 2013;6(11):2515-22.

3. Tang Q, Liu YF, Zhu XJ, Li YH, Zhu J, Zhang JP, Feng ZQ, Guan XH. Expression and prognostic significance of the alpha B-crystallin gene in human hepatocellular carcinoma. Hum Pathol. 2009;40(3):300-5. doi:10. 1016/j.humpath.2008.09.002.

4. Jemal A, Bray F, Center MM, Ferlay J, Ward E, Forman D. Global cancer statistics. CA Cancer J Clin. 2011;61(2):69-90. doi:10.3322/caac.20107.

5. Qu LS, Liu JX, Liu TT, Shen XZ, Chen TY, Ni ZP, Lu CH. Association of hepatitis B virus pre-S deletions with the development of hepatocellular carcinoma in Qidong, China. PLoS One. 2014;9(5):e98257. doi:10.1371/ journal.pone.0098257.

6. Zhang L, Liu FY, Fu JX, Duan F, Fan QS, Wang MQ. Hepatic arterial administration of sorafenib and iodized oil effectively attenuates tumor growth and intrahepatic metastasis in rabbit VX2 hepatocellular carcinoma model. Int J Clin Exp Pathol. 2014;7(11):7775-81.

7. Xu M, Xie F, Qian G, Jing Y, Zhang S, Gao L, Zheng T, Wu M, Yang J, Wei L. Peritumoral ductular reaction: a poor postoperative prognostic factor for hepatocellular carcinoma. BMC Cancer. 2014;14:65. doi:10.1186/1471-2407-14-65.

8. Liu WR, Tian MX, Jin L, Yang LX, Ding ZB, Shen YH, Peng YF, Zhou J, Qiu SJ, Dai Z et al. High expression of 5-hydroxymethylcytosine and isocitrate dehydrogenase 2 is associated with favorable prognosis after curative resection of hepatocellular carcinoma. J Exp Clin Cancer Res. 2014;33:32. doi:10.1186/1756-9966-33-32.

9. Wong RJ, Devaki P, Nguyen L, Cheung R, Nguyen MH. Ethnic disparities and liver transplantation rates in hepatocellular carcinoma patients in the recent era: results from the surveillance, epidemiology, and End results registry. Liver Transpl. 2014;20(5):528-35. doi:10.1002/lt.23820.

10. Marrero JA, El-Serag HB. Alpha-fetoprotein should be included in the hepatocellular carcinoma surveillance guidelines of the American Association for the Study of Liver Diseases. Hepatology. 2011;53(3):1060-1. doi:10.1002/hep.24033. author reply 1061-1062.

11. Zhan P, Ji YN. Prognostic significance of TP53 expression for patients with hepatocellular carcinoma: a meta-analysis. Hepatobiliary Surg Nutr. 2014; 3(1):11-7. doi:10.3978/j.issn.2304-3881.2014.01.03.

12. Budanov AV, Shoshani T, Faerman A, Zelin E, Kamer I, Kalinski H, Gorodin S, Fishman $A$, Chajut $A$, Einat $P$, et al. Identification of a novel stress-responsive gene Hi95 involved in regulation of cell viability. Oncogene. 2002;21(39): 6017-31. doi:10.1038/sj.onc.1205877.

13. Kim GT, Lee SH, Kim YM. Quercetin regulates sestrin 2-AMPK-mTOR signaling pathway and induces apoptosis via increased intracellular ROS in HCT116 colon cancer cells. J Cancer Prev. 2013;18(3):264-70.

14. Budanov AV, Sablina AA, Feinstein E, Koonin EV, Chumakov PM. Regeneration of peroxiredoxins by p53-regulated sestrins, homologs of bacterial AhpD. Science. 2004;304(5670):596-600. doi:10.1126/science.1095569.

15. Budanov AV, Karin M. p53 target genes sestrin1 and sestrin2 connect genotoxic stress and mTOR signaling. Cell. 2008;134(3):451-60. doi:10.1016/j.cell.2008.06.028.

16. Sablina AA, Budanov AV, Ilyinskaya GV, Agapova LS, Kravchenko JE, Chumakov PM. The antioxidant function of the p53 tumor suppressor. Nat Med. 2005;11(12):1306-13. doi:10.1038/nm1320.
17. Maiuri MC, Malik SA, Morselli E, Kepp O, Criollo A, Mouchel PL, Carnuccio R, Kroemer G. Stimulation of autophagy by the p53 target gene Sestrin2. Cell Cycle. 2009;8(10):1571-6.

18. Zhang $X Y, W u X Q$, Deng $R$, Sun $T$, Feng GK, Zhu XF. Upregulation of sestrin 2 expression via JNK pathway activation contributes to autophagy induction in cancer cells. Cell Signal. 2013;25(1):150-8. doi:10.1016/j.cellsig.2012.09.004.

19. Garber ME, Troyanskaya OG, Schluens K, Petersen S, Thaesler Z, PacynaGengelbach M, van de Rijn M, Rosen GD, Perou CM, Whyte Rl, et al. Diversity of gene expression in adenocarcinoma of the lung. Proc Natl Acad Sci U S A. 2001;98(24):13784-9. doi:10.1073/pnas.241500798.

20. Su LJ, Chang CW, Wu YC, Chen KC, Lin CJ, Liang SC, Lin CH, Whang-Peng J, Hsu SL, Chen CH, et al. Selection of DDX5 as a novel internal control for QRT-PCR from microarray data using a block bootstrap re-sampling scheme. BMC Genomics. 2007:8:140. doi:10.1186/1471-2164-8-140.

21. Sanli T, Linher-Melville K, Tsakiridis T, Singh G. Sestrin2 modulates AMPK subunit expression and its response to ionizing radiation in breast cancer cells. PLoS One. 2012;7(2):e32035. doi:10.1371/journal.pone.0032035.

22. Shin BY, Jin SH, Cho IJ, Ki SH. Nrf2-ARE pathway regulates induction of Sestrin-2 expression. Free Radic Biol Med. 2012;53(4):834-41. doi:10.1016/j. freeradbiomed.2012.06.026.

23. Liu W, Wang Y, Zhang C, Huang B, Bai J, Tian L. Cullin1 is up-regulated and associated with poor patients' survival in hepatocellular carcinoma. Int J Clin Exp Pathol. 2015;8(4):4001-7.

24. Gu X, Fu M, Ge Z, Zhan F, Ding Y, Ni H, Zhang W, Zhu Y, Tang X, Xiong L, et al. High expression of MAGE-A9 correlates with unfavorable survival in hepatocellular carcinoma. Scientific reports. 2014;4:6625. doi:10.1038/ srep06625.

25. Bao J, Ni Y, Qin H, Xu L, Ge Z, Zhan F, Zhu H, Zhao J, Zhou X, Tang X, et al. Rab27b is a potential predictor for metastasis and prognosis in colorectal cancer. Gastroenterol Res Pract. 2014;2014:913106. doi:10.1155/2014/913106.

26. Shi C, Yang X, Ni Y, Hou N, Xu L, Zhan F, Zhu H, Xiong L, Chen P. High Rab27A expression indicates favorable prognosis in CRC. Diagn Pathol. 2015; 10:68. doi:10.1186/s13000-015-0303-3.

27. Qin H, Ni Y, Tong J, Zhao J, Zhou X, Cai W, Liang J, Yao X. Elevated expression of CRYAB predicts unfavorable prognosis in non-small cell lung cancer. Med Oncol. 2014;31(8):142. doi:10.1007/s12032-014-0142-1.

28. Nogueira $\mathrm{V}$, Park $\mathrm{Y}$, Chen CC, Xu PZ, Chen ML, Tonic I, Unterman T, Hay N. Akt determines replicative senescence and oxidative or oncogenic premature senescence and sensitizes cells to oxidative apoptosis. Cancer Cell. 2008;14(6):458-70. doi:10.1016/j.ccr.2008.11.003.

29. Budanov AV, Lee $J H$, Karin M. Stressin' Sestrins take an aging fight. EMBO Mol Med. 2010;2(10):388-400. doi:10.1002/emmm.201000097.

30. Fogarty S, Hardie DG. Development of protein kinase activators: AMPK as a target in metabolic disorders and cancer. Biochim Biophys Acta. 2010; 1804(3):581-91. doi:10.1016/j.bbapap.2009.09.012.

31. Kim GT, Lee SH, Kim JI, Kim YM. Quercetin regulates the sestrin 2-AMPK-p38 MAPK signaling pathway and induces apoptosis by increasing the generation of intracellular ROS in a p53-independent manner. Int J Mol Med. 2014;33(4):863-9. doi:10.3892/ijmm.2014.1658.

32. Buitrago-Molina LE, Marhenke S, Longerich T, Sharma AD, Boukouris $A E$, Geffers R, Guigas B, Manns MP, Vogel A. The degree of liver injury determines the role of p21 in liver regeneration and hepatocarcinogenesis in mice. Hepatology. 2013;58(3):1143-52. doi:10.1002/hep.26412.

33. Wei JL, Fu ZX, Fang M, Guo JB, Zhao QN, Lu WD, Zhou QY. Decreased expression of sestrin 2 predicts unfavorable outcome in colorectal cancer. Oncol Rep. 2015;33(3):1349-57. doi:10.3892/or.2014.3701.

\section{Submit your next manuscript to BioMed Central and we will help you at every step:}

- We accept pre-submission inquiries

- Our selector tool helps you to find the most relevant journal

- We provide round the clock customer support

- Convenient online submission

- Thorough peer review

- Inclusion in PubMed and all major indexing services

- Maximum visibility for your research

Submit your manuscript at www.biomedcentral.com/submit
) Biomed Central 